\title{
An investigation of maternal mortality at a tertiary hospital of the Limpopo province of South Africa
}

\author{
Sam Thembelihle Ntuliab*t, Mabina Mogale ${ }^{c t}$, Francis LM Hyera ${ }^{\text {bt }}$ and Shan Naidoo ${ }^{d \dagger}$ \\ ${ }^{a}$ Research Development Administration, University of Limpopo, Sovenga, South Africa \\ 'Department of Public Health Medicine, University of Limpopo, Polokwane, South Africa \\ 'Department of Public Health: Epidemiology and Biostatistics, Sefako Makgatho Health Sciences University, Pretoria, South Africa \\ ${ }^{d}$ Department of Community Health, School of Public Health, University of the Witwatersrand, Johannesburg, South Africa \\ *Corresponding author, email: tsntuli@hotmail.com
}

Objective: To understand the elements influencing the maternal deaths in the Limpopo province, South Africa.

Methods: A retrospective review of all maternal deaths which occurred at the Pietersburg Hospital, Limpopo province was done over a five-year period (January 2011 to December 2015). The hospital death register was used to collate a list of maternal deaths occurring during the study period. The medical records of maternal deaths were reviewed. The total deliveries and live births for each year were obtained from the delivery registers. The data collected included maternal age, parity, referring facility, date of admission, date and time of death, ward where death occurred, and cause of death.

Results: There were 14685 live births and 232 maternal deaths between 2011 and 2015, resulting in an institutional Maternal Mortality Ratio (iMMR) of 1579/100 000 live births. The mean age of the patients was 29 years. Forty-three per cent of deaths occurred within 24 hours of admission, 35\% died in ICU and $89 \%$ were referred from regional and district hospitals and community health centres. Of the referred patients, $83 \%$ were from district hospitals. Obstetric haemorrhage and pre-eclampsia, or eclampsia, were the main causes of death.

Conclusion: The iMMR at Pietersburg Hospital remains unacceptably high. Most of the maternal deaths are due to obstetric haemorrhage, pre-eclampsia or eclampsia, medical and surgical disorder and non-pregnancy related infections.

Keywords: maternal, obstetric haemorrhage, pre-eclampsia or eclampsia, South Africa

\section{Introduction}

Maternal mortality is defined as the death of any woman while pregnant or within 42 days after delivery, miscarriage or termination of pregnancy, from any cause, excluding incidental causes. ${ }^{1,2}$ In South Africa (SA), the institutional Maternal Mortality Ratio (iMMR) decreased from 176.2/100 000 live births in 2008/2010 to $154.06 / 100000$ live births in $2011 / 2013 .{ }^{3}$ However, the burden of non-pregnancy-related infections, obstetric haemorrhage and pre-eclampsia or eclampsia remains unchanged. ${ }^{3}$

Studies in low-and-middle income countries reported a higher iMMR in the major tertiary referral hospitals where obstetrics complications are concentrated. These studies reported iMMR ranging from 100 to $1000 / 100000$ live births, ${ }^{4-9}$ while others have shown iMMR $>1000 / 100000$ live births. ${ }^{10-14}$ There are, however, other studies that have reported iMMR's lower than $100 / 100000$ live births. ${ }^{15-17}$ In a large urban referral hospital in SA, an iMMR of 105/100 000 live births between 1997 and 2009 was reported. ' The wide variations in iMMR in these studies could be due to socio-economic factors, delayed referrals from lower level facilities, lack of access to quality care, lack of infrastructure and insufficient numbers of qualified health personnel. Obstetric haemorrhage, pre-eclampsia or eclampsia and pregnancy-related sepsis are the major factors contributing to the higher iMMR among women in tertiary hospitals $\mathrm{s}^{4-14}$ and South Africa. ${ }^{3}$ Most maternal deaths are preventable if patients are given prompt appropriate treatment at the periphery, and are timeously and swiftly referred to higher centres. ${ }^{11,18,19}$

Despite the national decline in maternal mortality in SA, there is a considerable provincial variation in the $\mathrm{iMMR}$, with all provinces, with the exception of Limpopo, showing a reduction. ${ }^{3}$ Lack of senior or experienced doctors available to help junior and inexperienced doctors, lack of antenatal care, ineffective referral systems within health services and a lack of dedicated obstetric ICU staff may be factors contributing to most maternal deaths in Limpopo. ${ }^{15}$ Regional hospitals are expected to have specialists in their human resource compliment, a blood bank and a dedicated obstetric ICU. The Capricorn District of the Limpopo is the only region in the Province with a tertiary institution (Pietersburg Hospital), which serves as a referral hospital for 35 district and 5 regional hospitals. The epidemiological features of preventable maternal mortality and the reasons for high and ever-increasing maternal deaths in Limpopo have not been described in detail. ${ }^{20}$ Therefore, this study was carried out in a provincial tertiary hospital, Pietersburg Hospital, to understand the elements influencing the maternal deaths in Limpopo, South Africa.

\section{Materials and methods}

A retrospective descriptive study in which a review of all maternal deaths which occurred at Pietersburg Hospital of the Limpopo province, South Africa, was undertaken over a five-year period (January 2011 to December 2015). The hospital is located in the provincial capital, Polokwane, and is the only tertiary hospital in Limpopo. Pietersburg Hospital is the main referral hospital for maternal cases from all provincial public hospitals and, occasionally, from private hospitals in the province. The institution has a 12-bed multidisciplinary Intensive Care Unit (ICU), which admits about 350-450 patients on average per annum, while the maternity ward has 50 beds with an average of 300 deliveries per month (Hospital Statistics). Ethics approval to conduct the study was obtained from the Sefako Makgatho Health Sciences University Research Ethics Committee (SMUREC Ethics Ref \#: SMUREC/H/222/22015:IR). 
The hospital death register was used to identify and collate a list of maternal deaths that occurred during the study period. Medical records of maternal deaths were reviewed by the medical officer. Information on all the cases was extracted from the patient's case notes, labour unit registers and maternal mortality records. The total deliveries and live births for each year were obtained from the delivery registers. The anonymity and confidentiality of the patients' personal information was protected by a unique patient identifier. The data collected included maternal age, gestation age, referring facility, date of admission, date of death, ward where death occurred, and cause of death. Data was captured and analysed using Microsoft ${ }^{\circ}$ Excel (Microsoft Corporation) version 14 and STATA 9.0 (StataCorp; College Station, USA), respectively. Descriptive statistics was used to analyse data. Categorical variables are displayed as percentages and continuous variables are reported as mean \pm standard deviation (SD).

\section{Results}

A total of 14685 live births and 232 maternal deaths were reported over the five-year period of the study, resulting in a maternal mortality ratio of 1579 per 100000 live births (Table 1). The mean age of the women was $29 \pm 6.7$ (range from 15 to 48 years). Half (118/232) of the deaths occurred in those aged 30 years and older (Figure 1), and $53 \%(n=125)$ had a parity of 2 or more. Two-hundred and eight patients (89\%) were referred from regional and district hospitals, as well as community health centres $(\mathrm{CHCs})$. The majority (83\%) of the referred patients were from district hospitals. A greater proportion (35\%) of deaths occurred in intensive care and nearly half $(43 \%)$ of deaths occurred within 24 hours. The Chi-Square trend analysis shows no difference in the iMMR $(p=0.394)$.

Table 2 illustrates the yearly cause of maternal deaths during the period of the study. There were noticeable similarities over the years, with obstetric haemorrhage, pre-eclampsia or eclampsia,

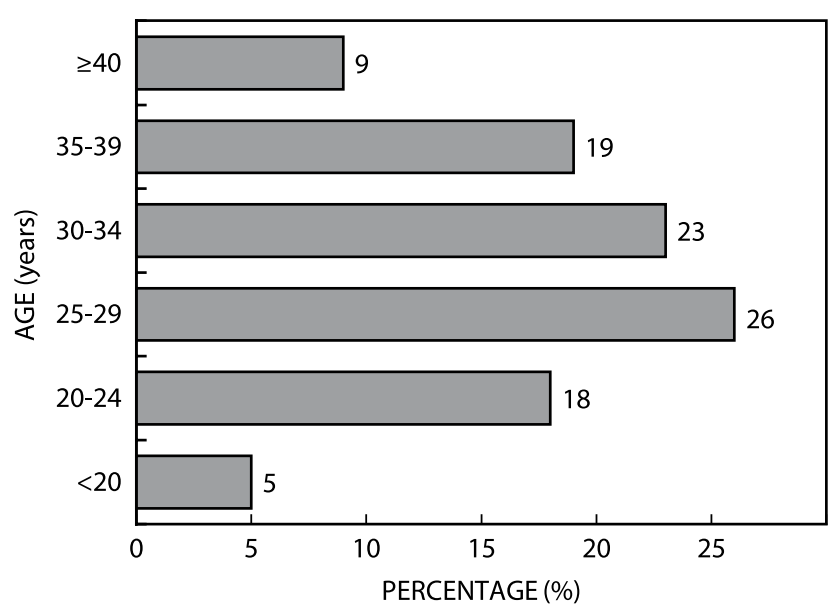

Figure 1: Age distribution of the patients.

Table 1: Trends in the MMR (2011-2015)

\begin{tabular}{|l|c|c|c|}
\hline Year & Live births & Deaths & iMMR/100 000 Live births \\
\hline 2011 & 2621 & 47 & 1793.2 \\
\hline 2012 & 2805 & 37 & 1319.1 \\
\hline 2013 & 2908 & 52 & 1788.2 \\
\hline 2014 & 3122 & 42 & 1345.3 \\
\hline 2015 & 3229 & 54 & 1672.3 \\
\hline Total & 14685 & 232 & 1579.8 \\
\hline
\end{tabular}

Table 2: Causes of maternal death at Pietersburg Hospital $(n=232)$

\begin{tabular}{|c|c|c|c|c|c|}
\hline & 2011 & 2012 & 2013 & 2014 & 2015 \\
\hline & $n(\%)$ & $n(\%)$ & $n(\%)$ & $n(\%)$ & $n(\%)$ \\
\hline Direct & & & & & \\
\hline Obstetric haemorrhage & $8(17)$ & $9(24)$ & $9(17)$ & $3(7)$ & $19(35)$ \\
\hline $\begin{array}{l}\text { Pre-eclampsia or } \\
\text { eclampsia }\end{array}$ & $13(28)$ & $7(19)$ & $9(17)$ & $5(12)$ & $6(11)$ \\
\hline $\begin{array}{l}\text { Anaesthetic compli- } \\
\text { cations }\end{array}$ & & & $1(2)$ & & $1(2)$ \\
\hline $\begin{array}{l}\text { Pregnancy related } \\
\text { sepsis }\end{array}$ & $7(15)$ & $6(16)$ & $5(10)$ & $9(21)$ & $5(10)$ \\
\hline Pulmonary embolism & & & $3(6)$ & $2(5)$ & $2(4)$ \\
\hline $\begin{array}{l}\text { Rupture ectopic preg- } \\
\text { nancy }\end{array}$ & $1(2)$ & & $1(2)$ & $2(5)$ & \\
\hline Indirect causes & & & & & \\
\hline $\begin{array}{l}\text { Medical/Surgical } \\
\text { condition }\end{array}$ & $8(17)$ & $7(19)$ & $10(19)$ & $10(24)$ & $11(20)$ \\
\hline $\begin{array}{l}\text { Non-pregnancy related } \\
\text { infections }\end{array}$ & $7(15)$ & $7(19)$ & $13(25)$ & $7(17)$ & $8(15)$ \\
\hline Unknown & $3(6)$ & $1(3)$ & $1(2)$ & $4(10)$ & $2(4)$ \\
\hline Total & 47 & 37 & 52 & 42 & 54 \\
\hline
\end{tabular}

Table 3: The causes of maternal deaths at Pietersburg Hospital (20112015)

\begin{tabular}{|l|c|c|}
\hline & $n$ & $\%$ \\
\hline Direct & & \\
\hline Obstetric haemorrhage & 48 & 21 \\
\hline Pre-eclampsia or eclampsia & 40 & 17 \\
\hline Anaesthetic complications (spinal) & 2 & 1 \\
\hline Pregnancy related sepsis & 32 & 14 \\
\hline Pulmonary embolism & 7 & 3 \\
\hline Rupture ectopic pregnancy & 4 & 2 \\
\hline Indirect causes & & \\
\hline Medical/Surgical condition & 46 & 20 \\
\hline Non-pregnancy related infections & 42 & 18 \\
\hline Unknown & 11 & 5 \\
\hline Total & 232 & \\
\hline
\end{tabular}

medical and surgical disorders mainly pulmonary oedema and renal failure and non-pregnancy related infections being the most common cause of maternal deaths. However, in 2014, pregnancy related sepsis was amongst the most prevalent causes.

Overall, as shown in Table 3, the top five leading causes of maternal deaths, in descending order were: obstetric haemorrhage; medical and surgical disorders; non-pregnancy related infections; pre-eclampsia or eclampsia; and, pregnancyrelated infections. These five conditions represent $90 \%$ of maternal causes of death at the study site during the study periods.

\section{Discussion}

From our study, the iMMR was 1579.3 per 100000 live births, worse than 105 per 100000 live births reported from an urban teaching hospital in Gauteng province, South Africa. ${ }^{1}$ The iMMR 
was also higher than the national average of 154.06 per 100000 live births. ${ }^{3}$ Our finding was consistent with various studies in developing countries ${ }^{10-14}$ in tertiary hospitals with iMMR $>1$ 000/100 000 live births. However, in some studies, iMMR was reported to range from 100 to $1000 / 100000$ live births, ${ }^{4-9}$ while other studies India, ${ }^{15}$ Kuwait $^{16}$ and Bangladesh ${ }^{17}$ found iMMR's lower than 100/100 000 live births. ${ }^{15-17}$ The reason for high iMMRs in our study is unclear; however, socio-economic deprivation, lack of antenatal care, lack of access to quality care in peripheral hospitals, lack of senior or experienced doctors available to help junior and inexperienced doctors in peripheral hospitals, ineffective referral systems within health services and lack of dedicated obstetric ICU may have contributed to these deaths. In addition, this hospital (Pietersburg Hospital) is inadequately resourced as far as personnel, equipment and other requirements for the management of these cases is concerned (Hospital Statistics).

It is worth noting that in the present study, eighty-nine percent (89\%) of maternal deaths occurred in patients who were referred - of which $(83 \%)$ were referrals from district hospitals. Lack of adequately skilled personnel, supplies and equipment in these hospitals could be the reasons for referrals from these hospitals. In our study, nearly half (43\%) of women died within 24 hours of admission, which is similar to the findings in other studies. ${ }^{4,21}$ The reasons for this must still be established; however, more than half (58\%) of these deaths occurred due to direct causes, mainly obstetric haemorrhage, pre-eclampsia or eclampsia, pregnancy related sepsis and pulmonary embolism.

Furthermore, our study shows that $35 \%$ of deaths occurred in ICU and a greater proportion of these deaths were due to obstetric haemorrhage, pre-eclampsia or eclampsia, and medical and surgical disorders. An earlier study in the same tertiary hospital found that $34.8 \%$ of the women admitted to the obstetric ICU died and the majority of these deaths were due to obstetric haemorrhage and pre-eclampsia or eclampsia. ${ }^{22}$ The reasons for high obstetric deaths in ICU were not investigated in this study. However, it is important to mention that most women were referred from peripheral hospitals, travelled long distances with an ambulance and died within 24 hour of admission, suggesting that the women were seriously ill before arrival at Pietersburg Hospital, and needed prompt appropriate intervention. ${ }^{22}$ This study has shown that maternal mortality in Limpopo may be high because of delayed intervention in peripheral hospitals.

In their study in India, Sharma and co-authors reported that women older than 34 years are at a higher risk of pregnancyrelated mortality. ${ }^{23}$ In the present study, a greater proportion of deaths occurred in women aged 30 years and older. Similar findings were reported by previous studies, ${ }^{21}$ but our findings differ from many studies which reported more deaths amongst women in the age group 20-29 years. 5,7,11,12 The reasons for the higher number of maternal deaths in women aged 30 years and older could be due to poverty, low education levels, lack of antenatal care, a greater numbers of children ${ }^{24}$ and complications related to chronic conditions. ${ }^{25}$ In this study, nearly half (48\%) of women in this age group had a parity of 3 or more and were from district hospitals although we did not assess the socio-economic status of the participants.

With regard to the causes of death: maternal deaths are usually caused by complications that arise before, during or after labour. This study found that obstetric haemorrhage, medical and surgical disorders, non-pregnancy-related infections, preeclampsia or eclampsia and pregnancy related infections were the most common causes. These findings are consistent with the national data. ${ }^{3}$ Similarly, these findings concur with reports by other investigators in other tertiary hospitals. ${ }^{4-9,11-14}$ Most of the haemorrhagic deaths in our study were due to postpartum haemorrhage. More than two-thirds (79\%) of haemorrhagic deaths occurred in patients from district hospitals, where longdistance travel to referral facilities, absence of a blood bank within the hospital premises, access to intensive care units, and inadequate staff numbers and/or competence may have been contributing factors. ${ }^{18}$

The Confidential Enquiries into Maternal Deaths in South Africa found that non-pregnancy related infections, mainly tuberculosis and pneumonia, accounted for $34.7 \%$ of maternal deaths from 2011 to 2013. ${ }^{3}$ However, a considerable reduction in nonpregnancy related infections was observed from 2008 to $2010 .^{3}$ Similar findings in which meningitis, pneumonia and tuberculosis were the leading cause of maternal death have been reported by Saini and Gupta. ${ }^{9}$ In this study, non-pregnancy related infections, namely tuberculosis, meningitis and pneumonia, were the main causes of maternal deaths; however, the rates of these deaths decreased with time. The reason for this decline could be due to an increase in the provision of HAART for pregnant women. ${ }^{3}$

Pulmonary oedema due to pre-eclampsia and multiple organ failure was the most common medical and surgical disorder found in the present study. Similarly, other studies have shown pulmonary oedema to be a frequent cause of maternal deaths; significantly more frequent than chronic hypertension and superimposed pre-eclampsia. ${ }^{26,27}$ In the present study, unknown causes of maternal deaths were dominated by herbal ingestion, which needs further investigation. Most of these deaths are preventable and may indicate relative inexperience with regard to the early identification and management of obstetric emergencies.

The high rate of maternal deaths reflects delayed management of labour complications, poor quality of maternal services and low socio-economic status of the community. ${ }^{8,28}$ Possible reasons for the high maternal mortality rate in our study are a lack of proper antenatal care, late referrals, poor transport facilities, lack of ICU beds, limited specialist obstetrician and critical care specialist support, lack of senior or experienced doctors available to help junior and inexperienced doctors in peripheral hospitals, long distances to the referral hospital and inadequate emergency obstetric care at referral centres close to patient residences. To reduce this high maternal mortality rate, it would be necessary for the provincial health department to implement audit processes to identify areas of improvement in obstetric care at the district and regional referring hospitals within the province. In addition, emergency obstetric interventions, such as prompt inter-facility transport of patients with pregnancy complications, have shown to offer a cost-effective way to improve maternal health outcomes across sub-Saharan Africa. ${ }^{19,29,30}$

\section{Study limitations}

As with retrospective studies, any missing data from patient files affects the reliability of the data, but this was minimised by reviewing admission and death registers and all files from the records department. Additionally, the recorded causes of death were based on a clinical assessment of the attending medical doctors. In the absence of post-mortem autopsy records, the correctness of the causes of death could not be verified. 


\section{Conclusion}

In conclusion, iMMR remains unacceptably high at the study site as compared to the national ratio. ${ }^{3}$ The top five leading causes of maternal death at Pietersburg Hospital, in descending order, were: obstetric haemorrhage, medical and surgical disorders, non-pregnancy related infection, pre-eclampsia or eclampsia, and pregnancy related infection. These five conditions represent $90 \%$ of causes of maternal deaths at this facility. A mix of multifaceted interventions is needed to address these excessive causes of maternal deaths in Limpopo.

Acknowledgements - We thank the staff of the Maternity Division and Records Division of the Pietersburg Hospital, especially KL Mohlake and T Esterhuyse for their assistance during this study. Thanks to Mrs ME Moshabela and Dr B Woldu for providing useful comments and suggestions.

Note

+ These authors contributed equally to this work.

\section{References}

1. Buchmann EJ, Mnyani CN, Frank KA, et al. Declining maternal mortality in the face of persistently high HIV prevalence in a middleincome country. BJOG. 2015 Jan;122(2):220-7. doi: 10.1111/14710528.13064. Epub 2014 Sep 12.

2. Soma-Pillay P, Pattinson RC, Langa-Mlambo L, et al. Maternal near miss and maternal death in the Pretoria Academic Complex, South Africa: a population-based study. S Afr Med J. 2015 Sep 21;105(7):578-63. doi: 10.7196/SAMJnew. 8038.

3. National Department of Health. South Africa saving mothers 20112013: fifth report on confidential enquiries into maternal deaths in South Africa. Pretoria: National Department of Health; 2015. [cited 2015 June 05]. Available from http://www.doh.gov.za.

4. Adu-Bonsaffoh K, Oppong SA, Binlinla G, et al. Maternal deaths attributable to hypertensive disorders in a tertiary hospital in Ghana. Int J Gynaecol Obstet. 2013 Nov;123(2):110-3. doi: 10.1016/j. ijgo.2013.05.017.

5. Sandhya Devi KVSM, Madhuri Ch, Sarada Bai K, et al. Study of maternal mortality in a tertiary care hospital. J Evol Med Dent Sci. 2015 May 11;4(38): 6624-30. doi:10.14260/jemds/2015/959.

6. Khan B, Deeba F, Khattak SN. Maternal mortality: a ten year review in a tertiary care setup. J Ayub Med Coll Abbottabad. 2012 Jul-Dec;24(34):124-7.

7. Yadav K, Namdeo A, Bhargava M. A retrospective and prospective study of maternal mortality in a rural tertiary care hospital of Central India. Indian J Community Health. 2013 Jan-Mar;25(1):16-21.

8. Yego F, Stewart Williams J, Byles J, et al. A retrospective analysis of maternal and neonatal mortality at a teaching and referral hospital in Kenya. Reprod Health. 2013 Feb;19(10):13. doi: 10.1186/1742-4755-10-13.

9. Saini V, Gupta M. Review of maternal mortality in urban tertiary care hospital of North India. Int J Basic and Appl Med Sci. 2014;4(1):59-64.

10. Garba M, Nayama M, Alio AP, et al. Maternal mortality in Niger: a retrospective study in a high risk maternity. Afr J Med Med Sci. 2011 Dec;40(4):393-7.

11. Pembe AB, Paulo C, D'mello BS, et al. Maternal mortality at Muhimbili National Hospital in Dar-es-Salaam, Tanzania in the year 2011. BMC Pregnancy Childbirth. 2014 Sep;13(14):320. doi:10.1186/1471-239314-320.
12. Fahim $F$, Nabeel N, Utman N. Trends in maternal mortality in tertiary care hospital in Peshawar - Pakistan. J Postgrad Med Inst. 2012;26(4):422-7.

13. Lee QY, Odoi AT, Opare-Addo H, et al. Maternal mortality in Ghana: a hospital-based review. Acta Obstet Gynecol Scand. 2012 Jan;91 (1):8792. doi: 10.1111/j.1600-0412.2011.01249.x.

14. Rulisa $S$, Umuziranenge I, Small $M$, et al. Maternal near miss and mortality in a tertiary care hospital in Rwanda. BMC Pregnancy Childbirth. 2015 Sep;3(15):203. doi: 10.1186/s12884-015-0619-8.

15. Khumanthem PD, Chanam MS, Samjetshabam RD. Maternal mortality and its causes in a tertiary center. J Obstet Gynaecol India. 2012 Apr;62(2):168-71. doi: 10.1007/s13224-012-0169-1.

16. Chibber R, Al-Hijji J, Al-Adwani AR, et al. Trends in maternal mortality over 29 years in a Kuwait Tertiary Teaching Hospital: signs of progress? J MaternFetal Neonatal Med. 2012 Sep;25(9):1557-63. doi: 10.3109/14767058.2011.640373.

17. Khatun K, Ara R, Aleem NT, et al. Maternal mortality in obstetrics and gynaecology in a tertiary care hospital. Mymensingh Med J. 2015 Jan;24(1):103-7.

18. Moodley J, Pattinson RC, Fawcus S, et al. The confidential enquiry into maternal deaths in South Africa: a case study. BJOG. 2014 Sep;121(Suppl 4):53-60. doi: 10.1111/1471-0528.12869.

19. Schoon MG. Impact of intet-facility transport on mortality in the Free State Province. S Afr Med J. 2013;103:534-8. https://doi.org/10.7196/ SAMJ.6828

20. Mothiba TM, Maputle MS, Tladi FM. Causes of maternal deaths in a tertiary hospital in Limpopo Province, South Africa: healthcare professionals' perspective. AJPHERD. 2013 Mar;Suppl 1:138-46.

21. Soomro S, Naz S, Memon N, et al. Causes of maternal deaths in a tertiary care hospital in Larkana. Pakistan Rawal Med J. 2013;38(3):271-4.

22. Ntuli TS, Ogunbanjo G, Nesengani $S$, et al. Obstetric intensive care admissions at a tertiary hospital in Limpopo Province, South Africa. South Afr J Crit Care. 2015;31(1):8-10. https://doi.org/10.7196/SAJCC.164

23. Sharma BR, Gupta N. Forensic considerations of pregnancy-related maternal deaths: an overview. J Forensic Leg Med. 2009;16:233-8. https://doi.org/10.1016/j.jfm.2008.12.005

24. Blanc AK, Winfrey W, Ross J. New findings for maternal mortality age patterns: aggregated results for 38 countries. PLoS ONE. 2013 Apr 16;8(4):1-9 e59864. doi: 10.1371/journal.pone.0059864. Print 2013.

25. Benli AR, Benli NC, Usta AT, et al. Effect of maternal age on pregnancy outcome and cesarean delivery rate. J Clin Med Res. 2015 Feb;7(2): 97-102. https://doi.org/10.14740/jocmr1904w

26. Thornton CE, von Dadelszen P,Makris A, etal. Acute pulmonary oedema as a complication of hypertension during pregnancy. Hypertens Pregnancy. 2011;30(2):169-79. doi: 10.3109/10641950902972140.

27. Dennis AT, Solnordal CB. Acute pulmonary oedema in pregnant women. Anaesthesia. 2012 Jun;67(6):646-59. doi: 10.1111/j.13652044.2012.07055.x. Epub 2012 Mar 15.

28. Sorensen BL, Elsass P, Nielsen BB, et al. Substandard emergency obstetric care - a confidential enquiry into maternal deaths at a regional hospital in Tanzania. Trop Med Int Health. 2010 Aug;15(8):894-900. doi: 10.1111/j.1365-3156.2010.02554.x.

29. Mucunguzi $S$, Wamani $H$, Lochoro $P$, et al. Effects of improved access to transportation on emergency obstetriccare outcomes in Uganda. Afr J Reprod Health. 2014;18:87-94. Medline: 25508044.

30. Tayler-Smith K, Zachariah R, Manzi M, et al. An ambulance referral network improves access to emergency obstetric and neonatal care in a district of rural Burundi with high maternal mortality. Trop Med Int Health. 2013 Aug;18(8):993-1001. doi: 10.1111/tmi.12121.

Received: 21-10-2016 Accepted: 08-02-2017 